\title{
CLINICAL AND RADIOGRAPHIC OUTCOMES OF IMMEDIATE IMPLANT PLACEMENT WITH OR WITHOUT NANOCRYSTALLINE BONE GRAFTING MATERIAL IN THE FACIAL GAP DISTANCE: A RANDOMIZED CLINICAL TRIAL
}

\author{
Waleed Mohamed Abbas* and Karim Mohamed Mahmoud Abdel Mohsen**
}

\begin{abstract}
Objectives: The aim of this study was to evaluate the clinical and radiographic outcomes of the simultaneous use of nanocrystalline bone grafting material placed in the facial gap distance around immediate dental implants placed in the anterior maxilla and its effect for minimizing the crestal bone loss.

Material and methods: Adult patients were eligible for the study if they needed one immediate implant placement (IIP) replacing a tooth to be extracted within the maxillary anterior region. The patients included in the study were divided into two groups; patients in the first group received IIP without grafting material in the gap distance while patients in the second group received IIP simultaneously with nanocrystalline bone in the facial gap distance. Clinical and radiographic assessments were performed before IIP (baseline) and scheduled 4 and 12 months after implant placement. Clinical assessment included bleeding Index (BI) and probing depth (PD). Facial bone height measurements were performed using cone beam computed tomography (CBCT) to measure the crestal bone loss.
\end{abstract}

Results: The means of BI and PD values at the 12 months follow up indicated healthy periimplant soft tissues for both groups, however higher means of BI and PD were shown in IIP without grafting material when compared to IIP with nanocrystalline bone in the facial gap distance. There was no statistically significant difference in CBL between both groups ( $\mathrm{p}=0.924)$.

Conclusions: The short-term follow-up of 12 months of IIP in the maxillary anterior area revealed successful clinical outcomes as assessed by objective parameters. IIP with or without simultaneous nanocrystalline bone grafting material placed in the facial gap distance around the implants did not prevent crestal bone loss as assessed by CBCT.

Keywords: extraction socket, remodeling, grafting, nanocrystalline, biomaterials, immediate implants, crestal bone loss.

* Lecturer of Oral Medicine, Periodontology and Oral Diagnosis, Ain Shams University and Future University.

** Lecturer of Oral and Maxillofacial Surgery, Faculty of Dentistry, Ain Shams University. 


\section{INTRODUCTION}

Immediate implant placed into fresh extraction socket is considered a predictable, safe, successful and acceptable procedure (Barone et al., 2006). However, immediate implant is considered aesthetically risky, as the healing of the alveolar bone may lead to unpredictable changes of the contour and the architecture of the gingival tissue around the implant. It has been proven that bone remodeling always takes place, even when an immediate implant is placed, as this phenomenon is associated with the resorption of the bundle bone, present only around the natural teeth. Therefore as bundle bone is a tooth-dependent tissue it will gradually disappear after tooth extraction. Since there is more bundle bone in the crest of the buccal than the lingual wall, hard tissue loss will be more pronounced in the buccal than the lingual wall (Araújo et al., 2005) (Araújo et al., 2006). Many protocols have been suggested to control or minimize the effects of bone healing process as flapless approach, the use of immediate implant supported provisional restoration or grafting of the alveolar space between the implant and the facial bony wall with different biomaterials (Blanco et al., 2008) (Chen, Darby and Reynolds, 2007) (Atieh et al., 2009). Over the past few years, the buccal wall thickness has gained significance, mainly as a result of its importance for the immediate implant placement (IIP) (Huynh-Ba et al., 2010). Although it is difficult measuring the thin buccal plate of bone around a metallic dental implant using cone beam computed tomography (CBCT), it is the only noninvasive approach to investigate the relationship between covering soft tissue and bone height and thickness around dental implant (Le and Borzabadi-Farahani, 2012). CBCT scans have been widely used in the dental field due to accuracy and the ability to view a detailed threedimensional image (3D) of the regions of interest (González-Martín et al., 2016).
It was demonstrated that the vertical bone loss and the gingival recession related to IIP can be reduced if $\geq 2 \mathrm{~mm}$ of labial bone thickness is maintained in the anterior region. In the same study, vertical bone loss and gingival recession showed a significant positive correlation, while bone width showed a significant negative correlation to gingival recession. The measurement of alveolar bone thickness and vertical bone loss in that study achieved through CBCT (Miyamoto and Obama, 2011). Another study using CBCT, the authors concluded that there was a low prevalence of buccal wall thicknesses $\geq 2 \mathrm{~mm}$ and that there was a moderately positive correlation between the buccal bone thickness and soft tissue (Younes et al., 2016)

The ideal grafting material to induce osseointegration should have osseoinductive and osseoconductive properties (Mavrogenis et al., 2009). The maturation and mineralization of the newly formed bone in the extraction socket can be accelerated or improved by graft materials (Mezzomo et al., 2011).

The use of xenograft for the reduction in dimensional alterations of a post-extraction site was already described in various animal studies (Araújo and Lindhe, 2005) (Araújo et al., 2005) (Araújo, Linder and Lindhe, 2011): in the latter, the authors showed that the use of Bio-Oss ${ }^{\circledR}$ Collagen graft to fill the buccal gap in a post-extraction implant reduced the buccal vertical resorption from $1.3 \pm$ $0.7 \mathrm{~mm}$ to $0.1 \pm 0.5 \mathrm{~mm}$.

Alloplast bone graft are widely used as bone substitutes for bone defect and accelerates the bone formation that filling the defect. Hydroxyapatite (HA) is one of the alloplast bone graft material which is characterized by its biocompatibility and bioactivity properties. One of the new generations of (HA) is nanohydroxyapetite, which is characterized by a porous structure. This nano / microstructure has particularly high porosity which showed balance between absorption of the nanohydroxyapetite 
particles and the rate of regenerative bone formation.

The present study was conducted to evaluate the clinical potential of nanocrystalline bone grafting material in the facial gap distance around immediate dental implants in the anterior maxilla and its significance in reducing crestal bone loss using CBCT.

Hypothesis: there is no clinical difference between immediate implant placement with simultaneous nanocrystalline grafting material in the facial gap distance and immediate implant placement without grafting material in the gap distance.

\section{AIM OF THE STUDY}

This research studied the clinical significance of using nanocrystalline bone grafting material in the facial gap distance around immediate dental implants in the anterior maxilla and its significance in reducing crestal bone loss.

\section{MATERIALS AND METHODS}

The present study was conducted on 14 patients; with age ranged from 21 to 50 years old and randomized into two equal groups (group1 and group 2). Each patient received one immediate implant in the anterior maxilla. The study protocol was approved by the ethical committee for clinical studies of Faculty of Dentistry, Ain Shams University. Patients were selected according to the inclusion and exclusion criteria from the outpatient clinic of the Faculty of Dentistry, Ain Shams University.

\section{Inclusion criteria:}

- Patients presented with the need for inevitable extraction of a single tooth in the maxillary anterior region (due to root fracture, root resorption, non-restorable remaining root or failed endodontic treatment).

- Good oral hygiene and good compliance with the plaque- control instructions.
- Natural teeth adjacent to the tooth to be extracted were required to have complete occlusal surfaces and were free from infections.

- The presence of intact buccal bone after tooth extraction as proved by exploring the labial plate of the socket using periodontal probe.

- At least $3 \mathrm{~mm}$ of bone beyond the root apex was required to guarantee implant primary stability.

- Patients' ability to follow the study protocol and willingness to sign an informed consent form.

\section{Exclusion criteria:}

- Inadequate soft tissue because of gingival attachment loss resulting in gingival recession, gingival asymmetry or mucogingival

- The presence of a fenestration $\leq 4 \mathrm{~mm}$ apical to the facial alveolar bone crest.

- Acute infection at the tooth site.

- Any systemic diseases or medications that could affect the osseointegration of the dental implants or compromise healing potential.

- Moderate and heavy smokers (>10 cigarettes per day).

An informed consent form was signed by all the patients participating in this study. All patients received standardized diagnosis and treatment planning procedures. This study was a randomized, double-blinded clinical trial with an equal allocation rate. Patients who met the eligibility criteria were randomly allocated using computer assisted randomization by Microsoft excel through numbered sealed envelopes into two groups. Both the patient and the evaluator who assessed the clinical parameters and CBCT were blinded to the group assignment.

\section{Group 1 (Gp 1)}

Each patient received one implant that was placed immediately following tooth extraction without flap elevation and without grafting material in the gap distance. 


\section{Group 2 (Gp 2)}

Each patient received one implant that was placed immediately following tooth extraction, simultaneously with nanocrystalline grafting material in the facial gap distance.

\section{Surgical Procedures:}

Atraumatic extraction was performed. No mucoperiostal flap was elevated. Subsequently, a periodontal probe* was used to verify the integrity of bony walls of the socket and the presence of dehiscence or fenestration defects (Chen and Buser, 2009). To be included, all of the four bony walls of the socket were intact. If a dehiscence defect of the facial bone was $\leq 2 \mathrm{~mm}$, the subject was included in the study (Degidi et al., 2013). Transmucosal sounding of the facial plate of bone was performed to detect the presence of any concavities apical to the socket (Chen and Buser, 2009). If a Fenestration of the facial bone was present $\geq 4 \mathrm{~mm}$ apical to the alveolar crest and the facial marginal bone was intact, the subject was included (Degidi et al., 2013). If the extraction socket met inclusion criteria, an implant** was placed after optimal osteotomy preparation through sequential drilling with copious irrigation according to the manufacturer instructions till the desired dimensions were achieved depending on the selected implant (Buser, Martin and Belser, 2004). The nanocrystalline bone grafting material ${ }^{* * *}$ was placed in the facial gap distance around the implant for group 2 patients.

For each patient of both groups; proper healing abutment was screwed to the implant at the end of the surgical procedure; approximation of the papillae was done by figure of eight suture. Postoperative medications were prescribed and instructions were explained for all patients.

\section{Prosthetic procedures:}

After complete soft tissue healing, 2 - 3 weeks later, a temporary prosthesis was fabricated for each patient of both groups using auto polymerizing acrylic resin. Four months after implant placement, the final abutment was screwed and conventional loading was applied using permanent porcelain fused to metal crown.

\section{Baseline and Follow-up evaluations:}

\section{Clinical examination}

Clinical examination was conducted by the same examiner to assess bleeding index score (BI) (Mombelli et al., 1987) and probing depth (PD) at baseline (before extraction), 4 months and 12 months post-surgical intervals.

\section{Radiographic examination}

Cone beam computed tomography (CBCT) using i-CAT $^{\text {TM **** }}$ was taken at the baseline, 4 months and at 12 months post-surgery in order to measure changes in height of the buccal plate of bone and calculate the vertical crestal bone loss (CBL). Standardization during imaging was achieved through adjusting the patient positioning lights as follow: The field of view (FOV) $(16 \mathrm{~cm} \mathrm{x} 6 \mathrm{~cm})$. Voxel size $=0.2 \mathrm{~mm}^{3}$ and scan time $=26.9$ seconds. To compare the vertical bone loss, fusion was done between baseline and 12 months post-surgery scans. Superimposition was done using Ondemand semiautomatic wizard, by selecting common points in both CBCT scans and then manual fine tuning was done to maintain the accuracy. The radiographic readings were performed by the same examiner

\section{Statistical analysis}

The mean and standard deviation values were calculated for each group in each test. Data were

\footnotetext{
* Helmut Zepf, Medizitechnik GmbH, Seitingen-Oberflacht, Germany

** Dentaurum Implants GmbH,Turnstraße, Ispringen, Germany

*** Artoss GmbH, Friedrich-Barnewitz-Straße 3,18119Rostock,Germany

**** iCAT Next Generation Cone Beam 3D System by Imaging Sciences International LLC, Hatfield, PA, USA
} 
explored for normality using Kolmogorov-Smirnov and Shapiro-Wilk tests, PD and CBL data showed parametric (normal) distribution, while BI data showed non-parametric (not-normal) distribution

For parametric data; Repeated measure ANOVA was used to compare between more than two groups in related samples. Paired sample t-test was used to compare between two groups in related samples. Independent sample t-test was used to compare between two groups in non-related samples.

Two-way ANOVA test was used to test the interactions between different variables.

For non-parametric data; Friedman was used to compare between more than two groups in related samples. Wilcoxon test was used to compare between two groups in related samples. Mann Whitney test was used to compare between two groups in non-related samples.

The significance level was set at $\mathrm{P} \leq 0.05$. Statistical analysis was performed with IBM ${ }^{\circledR}$ SPSS® Statistics Version 20 for Windows.

\section{RESULTS}

\section{Clinical outcomes:}

\section{Bleeding index scores (BI):}

No statistically significant difference was found between (Baseline), (4 months) and (12 months) follow up intervals in either (Group 1) or (Group 2) where $(p=0.056)$ and $(\mathrm{p}=0.104)$ respectively
There was no statistically significant difference between both groups at baseline $(\mathrm{p}=0.329)$, but there was a statistically significant difference between (Group 1) and (Group 2) at 4 months and 12 months follow up intervals where $(\mathrm{p}=0.008)$ and $(\mathrm{p}=0.001)$ respectively. Mean and standard deviation (SD) for BI for different tested groups are presented in (Table 1)

\section{Probing depth $(P D)$ :}

No statistically significant difference was found between (Baseline), (4 months) and (12 months) follow up intervals in either (Group 1) or (Group 2) where $(\mathrm{p}=0.149)$ and $(\mathrm{p}=0.164)$ respectively

There was no statistically significant difference between both groups at baseline and after 12 months where $(p=0.102)$ and $(p=0.162)$ respectively, while at 4 months follow up interval, there was a statistically significant difference between (Group 1) and (Group 2) $(\mathrm{p}=0.011)$. Mean and standard deviation (SD) for PD for different tested groups are presented in (Table 2)

\section{$>$ Two-way ANOVA:}

Data in table (3) shows the results of Two-way ANOVA analysis for the interaction of different variables. The results showed that groups had no statistically significant effect at P-value 0.067. Time had no statistically significant effect at P-value 0.313 . The interaction between the two variables had a statistically significant effect at P-value 0.012 .

TABLE (1): The mean, standard deviation (SD) values of BI of different groups.

\begin{tabular}{|c|c|c|c|c|c|c|c|}
\hline \multirow{3}{*}{ Variables } & \multicolumn{7}{|c|}{ BI } \\
\hline & \multicolumn{2}{|c|}{ Baseline } & \multicolumn{2}{|c|}{$4 m$} & \multicolumn{2}{|c|}{$12 \mathrm{~m}$} & \multirow[t]{2}{*}{ p-value } \\
\hline & Mean & SD & Mean & SD & Mean & SD & \\
\hline Group 1 & 0.690 & 0.150 & 0.929 & 0.302 & 0.929 & 0.131 & $0.056 \mathrm{~ns}$ \\
\hline Group 2 & 0.571 & 0.278 & 0.500 & 0.144 & 0.321 & 0.189 & $0.104 n s$ \\
\hline p-value & \multicolumn{2}{|c|}{$0.329 n s$} & \multicolumn{2}{|c|}{$0.008 *$} & \multicolumn{2}{|c|}{$0.001 *$} & \\
\hline
\end{tabular}

*; significant $(p<0.05) \quad n s ;$ non-significant $(p>0.05)$ 
TABLE (2): The mean, standard deviation (SD) values of PD of different groups.

\begin{tabular}{|c|c|c|c|c|c|c|c|}
\hline \multirow{3}{*}{ Variables } & \multicolumn{7}{|c|}{ PD } \\
\hline & \multicolumn{2}{|c|}{ Baseline } & \multicolumn{2}{|c|}{$4 m$} & \multicolumn{2}{|c|}{$12 \mathrm{~m}$} & \multirow[t]{2}{*}{ p-value } \\
\hline & Mean & SD & Mean & SD & Mean & SD & \\
\hline Group 1 & 2.570 & 0.460 & 3.711 & 0.872 & 3.233 & 1.084 & $0.149 n s$ \\
\hline Group 2 & 3.071 & 0.590 & 2.679 & 0.278 & 2.607 & 0.244 & $0.164 n s$ \\
\hline p-value & \multicolumn{2}{|c|}{$0.102 \mathrm{~ns}$} & \multicolumn{2}{|c|}{ 0.011* } & \multicolumn{2}{|c|}{$0.162 n s$} & \\
\hline
\end{tabular}

*; significant $(p<0.05) \quad n s ;$ non-significant $(p>0.05)$

TABLE (3) Results of Two-way ANOVA for the effect of different variables on PD.

\begin{tabular}{|c|c|c|c|c|c|}
\hline Source & $\begin{array}{c}\text { Type III Sum of } \\
\text { Squares }\end{array}$ & df & Mean Square & F & Sig. \\
\hline Corrected Model & 7.037 & 5 & 1.407 & 3.207 & .017 \\
\hline Intercept & 372.619 & 1 & 372.619 & 849.192 & .000 \\
\hline Groups & 1.562 & 1 & 1.562 & 3.560 & .067 \\
\hline Time & 1.053 & 2 & 2.211 & 5.039 & .313 \\
\hline Groups $*$ Time & 4.422 & 2 & .439 & & .012 \\
\hline Error & 15.797 & 36 & & & \\
\hline Total & 395.453 & 42 & & & \\
\hline Corrected Total & 22.833 & 41 & & & \\
\hline
\end{tabular}

$d f:$ degrees of freedom $=(n-1), *$ Significant at $P \leq 0.05$

TABLE (4): The mean, standard deviation (SD) values of CBL of different groups.

\begin{tabular}{|c|c|c|c|c|c|c|c|}
\hline \multirow{2}{*}{ Variables } & \multicolumn{7}{c|}{ CBL } \\
\cline { 2 - 8 } & \multicolumn{2}{|c|}{$\mathbf{0 - 4 m}$} & \multicolumn{2}{c|}{$\mathbf{4 m - 1 2 m}$} & \multicolumn{2}{c|}{$\mathbf{0 - 1 2 m}$} & \multirow{2}{*}{-value } \\
\cline { 2 - 8 } & Mean & SD & Mean & SD & Mean & SD & \\
\hline Group 1 & -0.904 & 0.613 & -0.334 & 0.466 & -1.239 & 0.790 & \multirow{2}{*}{$\mathbf{0 . 0 3 1 *}$} \\
\hline Group 2 & -0.914 & 0.204 & -0.329 & 0.192 & -1.269 & 0.194 & \multirow{2}{*}{$<\mathbf{0 . 0 0 1 *}$} \\
\hline p-value & \multicolumn{2}{|c|}{$\mathbf{0 . 9 6 8 n s}$} & \multicolumn{2}{|c|}{$\mathbf{0 . 9 7 7 n s}$} & \multicolumn{2}{c|}{$\mathbf{0 . 9 2 4 n s}$} & \\
\hline
\end{tabular}

*; significant $(p<0.05) \quad n s ;$ non-significant $(p>0.05)$ 


\section{Radiographic outcomes: Crestal bone loss} (CBL):

A statistically significant difference was found in (Group 1) between $(0-4 \mathrm{~m}),(4 \mathrm{~m}-12 \mathrm{~m})$ and $(0-12 \mathrm{~m})$ $(\mathrm{p}=0.031)$, where a statistically significant difference was found between $(4-12 \mathrm{~m})$ and $(0-12 \mathrm{~m})(\mathrm{p}=0.008)$, but no statistically significant difference was found between $(0-4 \mathrm{~m})$ and each of (4-12m) and (0-12m) where $(\mathrm{p}=0.091)$ and $(\mathrm{p}=0.106)$ respectively.

A statistically significant difference was also found in (Group 2) between (0-4m), (4m-12m) and
$(0-12 \mathrm{~m})(\mathrm{p}<0.001)$, where a statistically significant difference was found between $(0-4 \mathrm{~m})$ and each of $(4 \mathrm{~m}-12 \mathrm{~m})$ and $(0-12 \mathrm{~m})$ where $(\mathrm{p}=0.004)$ and $(\mathrm{p}=0.001)$. Also a statistically significant difference was found between $(4 m-12 m)$ and $(0-12 m)$ where $(\mathrm{p}<0.001)$.

There was no statistically significant difference between both groups at $(0-4 \mathrm{~m}),(4 \mathrm{~m}-12 \mathrm{~m})$ and $(0-$ $12 \mathrm{~m})$ where $(\mathrm{p}=0.968),(\mathrm{p}=0.977)$ and $(\mathrm{p}=0.924)$ respectively. Mean and standard deviation (SD) for CBL for different tested groups are presented in (Table 4) and (Figure 1)

TABLE (5) Results of Two-way ANOVA for the effect of different variables on CBL.

\begin{tabular}{|c|c|c|c|c|c|}
\hline Source & $\begin{array}{c}\text { Type III Sum of } \\
\text { Squares }\end{array}$ & Df & Mean Square & F & Sig. \\
\hline Corrected Model & 6.083 & 5 & 1.217 & 5.475 & .001 \\
\hline Intercept & 29.033 & 1 & 29.033 & 130.645 & .000 \\
\hline Groups & .001 & 1 & .001 & 13.679 & .038 \\
\hline Time & 6.080 & 2 & 3.040 & .005 & .000 \\
\hline Groups* Time & .002 & 2 & .222 & & .995 \\
\hline Error & 8.000 & 36 & & & \\
\hline Total & 43.117 & 42 & & & \\
\hline Corrected Total & 14.084 & 41 & & & \\
\hline
\end{tabular}

df: degrees of freedom $=(n-1), *$ Significant at $P \leq 0.05$

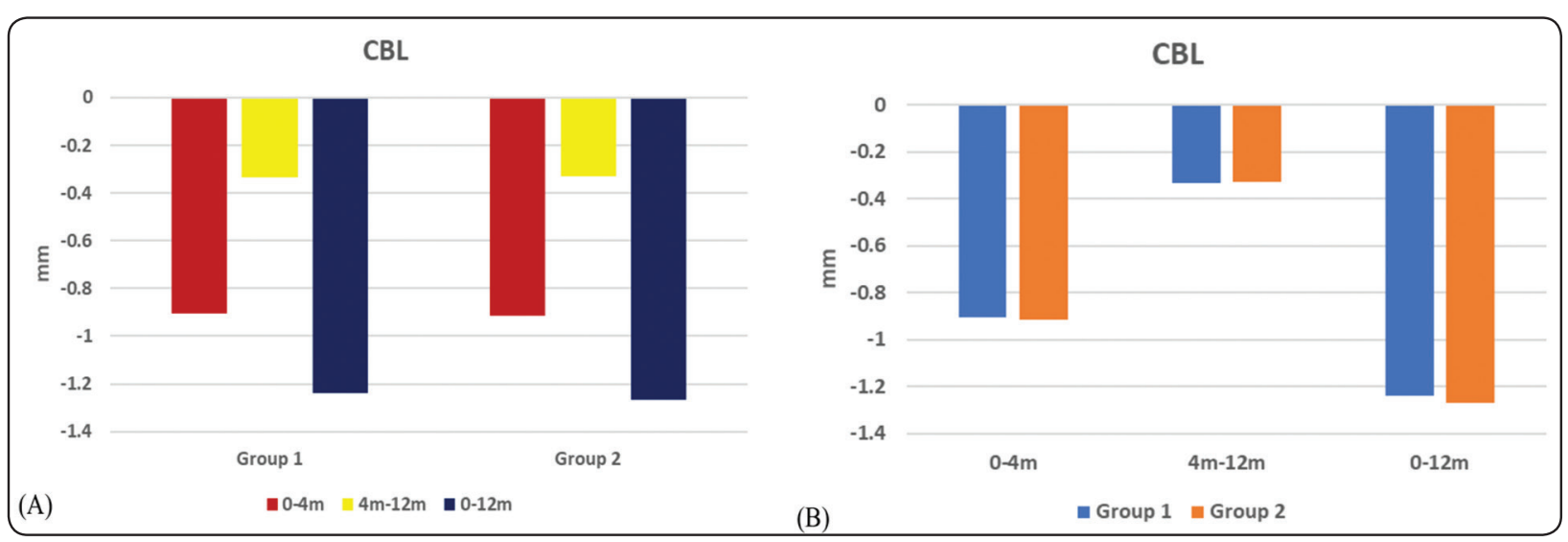

Fig. (1): Bar chart representing CBL for different groups 


\section{Two-way ANOVA:}

Data in table (5) shows the results of Two-way ANOVA analysis for the interaction of different variables. The results showed that groups had no statistically significant effect at P-value 0.938. Time had a statistically significant effect at P-value $<0.001$. The interaction between the two variables had no statistically significant effect at P-value 0.995 .

\section{DISCUSSION}

In immediate implant placement (IIP), the horizontal peri-implant gap appeared to affect the healing of bone around the implant. It was shown that when the horizontal width of a peri-implant defect was less than $2 \mathrm{~mm}$, the defect had the capacity to spontaneously heal and produce new bone when immediate implant placement was performed. But when the peri-implant gap width was more than $2 \mathrm{~mm}$, bone graft material with or without membrane should be used to seal this defect for proper esthetic outcome (Paolantonio et al., 2001).

It was postulated that nanocrystalline bone grafting material embedded in a silica gel matrix has osteoconductive and showed biodegradation in a manner comparable to natural bone remodeling processes. Graft resorption and appear in conjunction with bone apposition around the graft granules (Götz et al., 2008). IIP with hydroxyapatite nanocrystals bone graft material showed high significant increase in values of bone density and implant stability more than IIP without any graft material after 6 months postoperative.(Ghanem, Hashem and Mostafa, 2016)

NanoBone ${ }^{\circledR}$ is an approved granular material consisting of nanocrystalline HA embedded in a silica gel matrix which offers advantages of nanostructural biomaterials (Webster and Ahn, 2006). Gerber et al attributed that Nanobone ${ }^{\circledR}$ is able to stimulate the differentiation of bone cells into osteoblasts and osteoclasts, because alkaline phosphatase , osteocalcin, osteopontin and BMP-2 were located in newly formed bone (Gerber et al., 2006).

The use of collagen membrane and Nanobone can significantly reduce the horizontal resorption of the alveolar ridge and preserve keratinized tissue more effectively than blood clot alone and natural healing of single-rooted extraction sockets (Salahi , Etemadifar and Moosaali, 2015)

A histomorphometric analysis in an experimental study showed that nanocrystalline bone grafting material with platelet rich fibrin (PRF) significantly preserve the dimensions of extracted bony socket after atraumatic simple extraction (Ghanem et al 2016)

According to the previous studies, the role of nanocrystalline hydroxyapatite as alloplast material in establishment of high success osseointegration of immediate implants and minimizing crestal bone loss needs to be investigated.

The aim of the present study was to evaluate the clinical and radiographic outcomes of the simultaneous use of nanocrystalline bone grafting material placed in the facial gap distance around immediate dental implants placed in the anterior maxilla and its effect for minimizing the crestal bone loss.

The findings from this study showed that implants placed in fresh extraction sites can provide a safe and successful treatment procedure.

This study showed $100 \%$ survival rate of immediate implants. This result is in accordance with Kan et al. who showed a survival rate of $100 \%$ for 35 implants that were placed and immediately restored after tooth extraction (Kan et al., 2011).

The means of $\mathrm{BI}$ and PD values at the 12 months follow up indicated healthy peri-implant soft tissues. The reduction in the inflammatory reaction could be attributed to the strong patient's motivation 
for oral hygiene measures. The results of the current study agreed with the findings of other investigators who reported that plaque accumulation can induce a negative mucosal response (Kan et al., 2018) .

The results of the present study are consistent with the findings of other investigators, who reported that marginal tissue around titanium fixtures, in most examined patients had no gingivitis throughout the study (Buser, Weber and Lang, 1990).

Clinical probing is considered as an important and reliable diagnostic parameter in the continuous monitoring of both periodontal and peri-implant tissues (Atassi, 2002).The results of the present study demonstrated that there was no statistically significant difference in BI and PD throughout the study periods within each group. However, there was a statistically significant difference in mean of BI between both groups at 4 months and 12 months follow up intervals where in the latter, the mean BI related to implants placed immediately following teeth extraction without nanocrystalline bone was significantly more than that related to implants placed immediately following teeth extraction with simultaneous nanocrystalline bone placed in the facial gap distance around the implants. There was also a statistically significant difference in mean of PD between both groups at 4 months follow up interval where the mean PD related to implants placed immediately following teeth extraction without grafting material was significantly more than that related to implants placed immediately following teeth extraction with simultaneous grafting material placed in the facial gap distance around the implants, but no statistically significant difference was found in mean of PD between both groups after 12 months.

Many authors showed that the insertion of implants immediately after the extraction is a valuable technique in terms of success and esthetic outcomes (Paolantonio et al., 2001) (Cornelini et al., 2006) (J. et al., 2011). In 2010, Sanz et al. showed that in implants inserted in post-extractive sites without graft, a mean vertical crest reduction of $1 \pm 2 \mathrm{~mm}$ occurred in the buccal side (Sanz et al., 2010).

The thickness of the buccal bone wall can determine the degree to which vertical resorption is produced. Sites with thin facial bone underwent significantly more vertical resorption than sites with thicker facial bone (Chung et al., 2011). Mean bone level change around immediate implants is affected by the gap distance between the socket wall and the implant, it was reported that if the jumping distance is over $2 \mathrm{~mm}$, grafting is recommended. Smaller distances could heal spontaneously (Chen, Wilson and Hämmerle, 2004) (Esposito et al., 2009) .

Concerning the mean crestal bone loss (CBL), both groups of the present study showed CBL during the whole study follow up (0-12months) which was statistically significant for both groups but there was no statistically significant difference between both groups $(\mathrm{p}=0.924)$.

These findings were in agreement with findings reported in a recent systematic review in which it was concluded that marginal bone loss occurred most often during the first year after implant placement and with a magnitude of about $0.8-1.0 \mathrm{~mm}$ (Lang et al., 2012), while these findings were in contrary to another study in which clinical evaluation of immediate implants using either freeze-dried bone allograft or modified hydroxyapatite revealed significant decrease in bone height through one year follow up (Viswambaran et al., 2014).

Many studies reported that lack of flap elevation does not prevent bone resorption but the major benefit of this treatment is the preservation of the existing papillae (Migliorati et al., 2015). CBL can be minimized through proper case selection, intact socket wall after atraumatic extraction, adequate bone for achieving primary stability, flapless technique, placement of a slowly resorbing grafting material in the gap between the implant and the 
buccal socket wall and correct three-dimensional implant positioning. The present radiographic study seems to confirm that, even in the presence of dimensional alterations of the alveolar ridge, it is possible to minimize the effect of these alterations on the buccal side of the implant.

Limitations of the present study: Short-term follow-up and Small sample size of each group

\section{CONCLUSIONS}

Within the limitations of this study, it was concluded that:

- Immediate implant placement in the maxillary anterior area revealed successful clinical outcomes as assessed by objective parameters through short-term follow-up of 12 months

- Immediate implant placement with simultaneous nanocrystalline bone grafting material placed in the facial gap distance around the implants did not prevent crestal bone loss during the first year after implant placement as assessed by cone beam computed tomography analysis.

\section{Recommendations}

- Future randomized controlled trials should include a longer follow-up and a larger sample size, to assess if immediate implant placement with simultaneous nanocrystalline bone grafting material offers long-term benefits for patients with thin facial bone biotype

- Comparison of long term stability of soft tissue around immediate implant placement with or without simultaneous nanocrystalline bone grafting material.

\section{REFERENCES}

- $\quad$ Araújo, M. G. et al. (2005) 'Ridge alterations following implant placement in fresh extraction sockets: An experimental study in the dog', Journal of Clinical Periodontology, 32(6), pp. 645-652 .doi: 10.1111/j.1600051X.2005.00726.x.
- $\quad$ Araújo, M. G. et al. (2006) 'Tissue modeling following implant placement in fresh extraction sockets', Clinical Oral Implants Research, 17(6), pp. 615-624. doi: 10.1111/j.1600-0501.2006.01317.x

- Araújo, M. G., Linder, E. and Lindhe, J. (2011) 'BioOss ${ }^{\circledR}$ Collagen in the buccal gap at immediate implants: A 6-month study in the dog', Clinical Oral Implants Research, 22(1), pp. 1-8. doi: 10.1111/j.1600-0501.2010.01920.x.

- Araújo, M. G. and Lindhe, J. (2005) 'Dimensional ridge alterations following tooth extraction. An experimental study in the dog', Journal of Clinical Periodontology, 32(2), pp. 212-218. doi: 10.1111/j.1600-051X.2005.00642.x.

- Atassi, F. (2002) 'Periimplant Probing: Positives and Negatives', Implant Dentistry, 11(4), pp. 356-362. doi: 10.1097/00008505-200211040-00015.

- Atieh, M. A. et al. (2009) 'Immediate restoration/loading of immediately placed single implants: Is it an effective bimodal approach?: Review', Clinical Oral Implants Research, 20(7), pp. 645-59 . doi: 10.1111/j.16000501.2009.01725.x.

- $\quad$ Barone, A. et al. (2006) 'Immediate Restoration of Single Implants Placed Immediately After Tooth Extraction', Journal of Periodontology, 77(11), pp. 1914-1920. doi: 10.1902/jop.2006.060072.

- Blanco, J. et al. (2008) 'Ridge alterations following immediate implant placement in the dog: Flap versus flapless surgery', Journal of Clinical Periodontology, 35(7), pp. 640-648. doi: 10.1111/j.1600-051X.2008.01237.x.

- $\quad$ Buser, D., Martin, W. and Belser, U. C. (2004) 'Optimizing esthetics for implant restorations in the anterior maxilla: anatomic and surgical considerations.', The International journal of oral \& maxillofacial implants, 19,pp. 43-61.

- $\quad$ Buser, D., Weber, H. -P and Lang, N. P. (1990) 'Tissue integration of non-submerged implants. 1-year results of a prospective study with 100 ITI hollow-cylinder and hollow-screw implants.', Clinical Oral Implants Research, 1(1),pp. 33-40. doi: 10.1034/j.1600-0501.1990.010105.x.

- Chen, S. T. and Buser, D. (2009) 'Clinical and esthetic outcomes of implants placed in postextraction sites.', The International journal of oral \& maxillofacial implants, 24 Suppl, pp. 186-217

- Chen, S. T., Darby, I. B. and Reynolds, E. C. (2007) 'A prospective clinical study of non-submerged immediate implants: Clinical outcomes and esthetic results', 
Clinical Oral Implants Research, 18(5), pp. 552-562. doi: 10.1111/j.1600-0501.2007.01388.x.

- $\quad$ Chen, S. T., Wilson, T. G. and Hämmerle, C. H. F. (2004) 'Immediate or early placement of implants following tooth extraction: review of biologic basis, clinical procedures, and outcomes.', The International journal of oral \& maxillofacial implants, 19(supp.), pp.12-25.

- Chung, S. et al. (2011) 'Immediate single tooth replacement with subepithelial connective tissue graft using platform switching implants: A case series', Journal of Oral Implantology, 37(5), pp. 559-69. doi: 10.1563/ AAID-JOI-D-10-00110.

- Cornelini, R. et al. (2005) 'Immediate restoration of implants placed into fresh extraction sockets for singletooth replacement: A prospective clinical study', The International journal of periodontics \& restorative dentistry, 25(5), pp.439-47. doi: 10.1016/j.prosdent.2006.03.007.

- Degidi, M. et al. (2013) 'Buccal bone plate in immediately placed and restored implant with Bio-Oss ${ }^{\circledR}$ collagen graft: A 1-year follow-up study', Clinical Oral Implants Research, 24(11), pp. 1201-5. doi: 10.1111/j.16000501.2012.02561.x.

- Esposito, M. et al. (2009) 'Interventions for replacing missing teeth: Bone augmentation techniques for dental implant treatment', Australian Dental Journal, 54(1), pp. 70-71. doi: 10.1111/j.1834-7819.2008.01093.x.

- Gerber, T. et al. (2006) 'Nanostructuring of biomaterials A pathway to bone grafting substitute', European Journal of Trauma, 32(2), pp. 132-140. doi: 10.1007/s00068-0066046-9.

- $\quad$ Ghanem, W., Hashem, A. and Mostafa, M. (2016) 'Effect of hydroxyapatite nano-crystals on bone healing around immediate dental implant', Egyptian Dental Journal, 62(2), pp. 2291:2297.

- Ghanem, W. et al (2016) 'Effect of nanobone graft on socket healing after teeth extraction', Egyptian Dental Journal, 62(3), pp. 3547:3553.

- González-Martín, O. et al. (2016) 'Evaluation of periimplant buccal bone by computed tomography: An experimental study', Clinical Oral Implants Research, 27(8), pp. 950-955. doi: 10.1111/clr.12663.

- Götz, W. et al. (2008) 'Immunohistochemical characterization of nanocrystalline hydroxyapatite silica gel (NanoBone $\left.{ }^{\circledR}\right)$ osteogenesis: A study on biopsies from human jaws', Clinical Oral Implants Research, 19(10), pp. 1016-26. doi: 10.1111/j.1600-0501.2008.01569.x.

- Huynh-Ba, G. et al. (2010) 'Analysis of the socket bone wall dimensions in the upper maxilla in relation to immediate implant placement', Clinical Oral Implants Research, 21(1), pp. 37-42. doi: 10.1111/j.1600-0501.2009.01870.x.

- J., C. et al. (2011) 'Immediate single-tooth implants in the anterior maxilla: 3-year results of a case series on hard and soft tissue response and aesthetics', Journal of Clinical Periodontology, 38(8), pp. 746-53. doi: 10.1111/j.1600051X.2011.01748.x.

- Kan, J. Y., Rungcharassaeng, K., Lozada, J. L. \& Zimmerman, G. (2011) 'Facial gingival tissue stability following immediate placement and provisionalization of maxillary anterior single implants: a 2-to 8-year follow-up', International Journal of Oral \& Maxillofacial Implants, 26(1), pp. 179-187.

- Kan, J. Y. K. et al. (2018) 'Immediate implant placement and provisionalization of maxillary anterior single implants', Periodontology 2000, 77(Suppl. 1), pp. 1-16. doi: 10.1111/prd.12212.

- $\quad$ Lang, N. P. et al. (2012) 'A systematic review on survival and success rates of implants placed immediately into fresh extraction sockets after at least 1 year', Clinical Oral Implants Research, 23 (Suppl 5), pp. 39-66. doi: 10.1111/j.1600-0501.2011.02372.x.

- $\quad$ Le, B. T. and Borzabadi-Farahani, A. (2012) 'Labial bone thickness in area of anterior maxillary implants associated with crestal labial soft tissue thickness', Implant Dentistry, 21(5), pp. 406-410. doi: 10.1097/ID.0b013e31826371b5.

- Mavrogenis, A. F. et al. (2009) 'Biology of implant osseointegration', Journal of Musculoskeletal Neuronal Interactions, 9(2), pp. 61-71.

- Mezzomo, L. A. et al. (2011) 'Alveolar ridge preservation after dental extraction and before implant placement: A literature review', Revista Odonto Ciencia, 26(1), pp. 7783. doi: 10.1590/S1980-65232011000100017.

- Migliorati, M. et al. (2015) 'Clinical and Aesthetic Outcome with Post-Extractive Implants with or without Soft Tissue Augmentation: A 2-Year Randomized Clinical Trial', Clinical Implant Dentistry and Related Research, 17(5), pp. 983-995. doi: 10.1111/cid.12194.

- Miyamoto, Y. and Obama, T. (2011) 'Dental cone beam computed tomography analyses of postoperative 
labial bone thickness in maxillary anterior implants: comparing immediate and delayed implant placement.', The International journal of periodontics \& restorative dentistry, 31(3), pp. 215-225. doi: 10.11607/prd.00.0980.

- $\quad$ Mombelli, A. et al. (1987) 'The microbiota associated with successful or failing osseointegrated titanium implants', Oral Microbiology and Immunology, 2(4), pp. 145-151. doi: 10.1111/j.1399-302X.1987.tb00298.x.

- Paolantonio, M. et al. (2001) 'Immediate Implantation in Fresh Extraction Sockets. A Controlled Clinical and Histological Study in Man', Journal of Periodontology, 72(11), pp. 1560-71. doi: 10.1902/jop.2001.72.11.1560.

- $\quad$ Salahi, S., Etemadifar, R., \& Fereshteh, M. (2015) 'Morphometric Changes of the Socket after Site Preservation Using Nanobone and Collagen Membrane or Stypro Versus Extraction Alone', J Dent Biomater, 2(2), pp. 54-60.
- Sanz, M. et al. (2010) 'A prospective, randomizedcontrolled clinical trial to evaluate bone preservation using implants with different geometry placed into extraction sockets in the maxilla', Clinical Oral Implants Research, 21(1), pp. 13-21. doi: 10.1111/j.1600-0501.2009.01824.x.

- Viswambaran, M. et al. (2014) 'Clinical evaluation of immediate implants using different types of bone augmentation materials', Medical Journal Armed Forces India, 70(2), pp. 154-62. doi: 10.1016/j.mjafi.2012.04.020.

- Webster, T. J. and Ahn, E. S. (2006) 'Nanostructured Biomaterials for Tissue Engineering Bone', in Lee K. and Kaplan D. (eds). Tissue Engineering II. Advances in Biochemical Engineering/Biotechnology, vol 103. Berlin, Heidelberg: Springer, pp 275-308. doi: 10.1007/10_021.

- Younes, F. et al. (2016) 'Relationship between buccal bone and gingival thickness revisited using non-invasive registration methods', Clinical Oral Implants Research, 27(5), pp. 523-528. doi: 10.1111/clr.12618. 